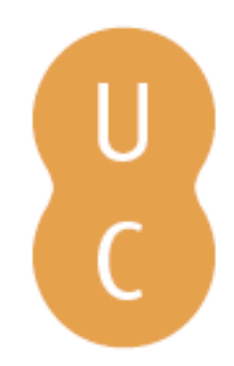

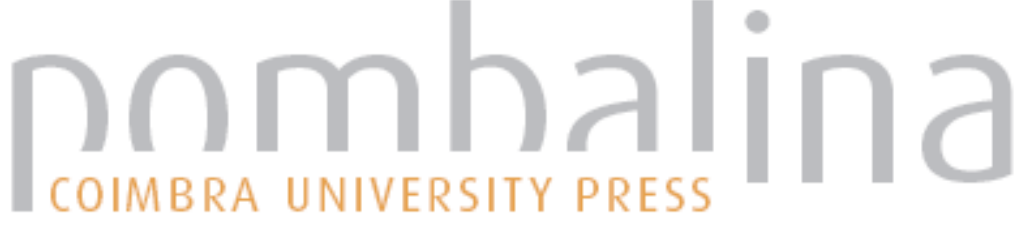

\section{Injuries in youth sports}

\author{
Autor(es): $\quad$ Malina, Robert M \\ Publicado por: Coimbra University Press \\ URL \\ persistente: \\ URI:http://hdl.handle.net/10316.2/32635 \\ DOI: \\ DOI:http://dx.doi.org/10.14195/978-989-26-0412-1_19
}

Accessed : $\quad$ 26-Apr-2023 01:17:30

A navegação consulta e descarregamento dos títulos inseridos nas Bibliotecas Digitais UC Digitalis, UC Pombalina e UC Impactum, pressupõem a aceitação plena e sem reservas dos Termos e Condições de Uso destas Bibliotecas Digitais, disponíveis em https://digitalis.uc.pt/pt-pt/termos.

Conforme exposto nos referidos Termos e Condições de Uso, o descarregamento de títulos de acesso restrito requer uma licença válida de autorização devendo o utilizador aceder ao(s) documento(s) a partir de um endereço de IP da instituição detentora da supramencionada licença.

Ao utilizador é apenas permitido o descarregamento para uso pessoal, pelo que o emprego do(s) título(s) descarregado(s) para outro fim, designadamente comercial, carece de autorização do respetivo autor ou editor da obra.

Na medida em que todas as obras da UC Digitalis se encontram protegidas pelo Código do Direito de Autor e Direitos Conexos e demais legislação aplicável, toda a cópia, parcial ou total, deste documento, nos casos em que é legalmente admitida, deverá conter ou fazer-se acompanhar por este aviso. 
MANUEL COELHO E SILVA

ROBERT M. MALINA

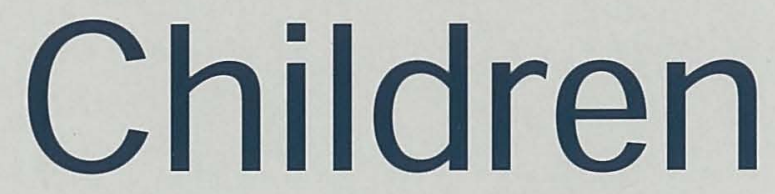

\section{and Youth}

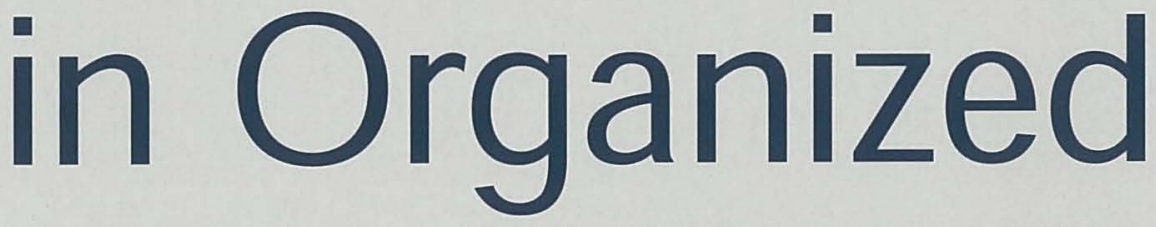

Sports 
(Página deixada propositadamente em branco) 
Manuel Coelho e Silva

Robert M. Malina

(Editors)

CHILDREN AND YOUTH IN ORGANIZED SPORTS

COIMBRA UNIVERSITY PRESS

2004 


$$
\begin{gathered}
\text { Editors } \\
\text { Manuel Coelho e Silva } \\
\text { and } \\
\text { Robert M. Malina } \\
\text { Publisher } \\
\text { Imprensa da Universidade de Coimbra } \\
\text { Coimbra University Press } \\
\text { Title } \\
\text { Children and Youth in Organized Sports }
\end{gathered}
$$

Date

March 2004

ISBN

972-8704-21-6

(Depósito legal n.: 208058/04)

Financial support

FCT Fundação para a Ciência e a 'Tecnologia MINISTÉRIO DA CIÊNCIA E DO ENSINO SUPERIOR Portugal

$$
\text { Apoio do Programa Operacional }
$$

Ciência, Tecnologia, Inovação do Quadro Comunitário de Apoio III

e

Câmara Municipal da Lousã

Faculdade de Ciências do Desporto e Educação Física

Universidade de Coimbra 


\section{INJURIES IN YOUTH SPORTS}

Robert M Malina

Fellow of the American College of Sports Medicine. Research Professor. Tarleton State University. Stephenville. TX

UNITED STATES OF AMERICA

\section{INTRODUCTION}

Injury in sport is commonly discussed in the medical and youth sport communities, but there is generally more public health concern for childhood injuries and injury-related deaths associated with automobiles (occupant and pedestrian), bicycles (especially traffic-related), firearms, drowning, fire, poison, and falls (Behrman, 2000). Nevertheless, risk of injury is inherent in sports and many other activities of childhood and adolescence. It is not clear, however, whether injuries in organized youth sports occur at a higher rate than in other activities of children and adolescents. This chapter provides an overview of concepts, issues and sources of information related to injuries in youth sports.

\section{WHAT IS AN INJURY?}

There are no standardized definitions of an injury in sport, including youth sport. For example, an injury has been defined as an incident that requires the participant to miss all or part of a practice or game (DeLee and Farney, 1992), and as a disabling event evaluated by a trainer or physician at a practice and/or game that requires cessation of play (Roberts et al., 1999). An American College of Sports Medicine Roundtable on Injuries in Youth Sports (Kohl et al., 1996) suggests that a sports injury "... is an adverse event which occurs during an organized training session, practice, and/or event, and which restricts participation in that sport for at least 24 hours." The National Athletic Trainer's Association (NATA) injury surveillance of high school sports used an expanded concept of a "reportable injury," which was defined by several criteria:

"Any injury that causes cessation of participation in the current game or practice and prevent's the player's return to that session.

"Any injury that causes cessation of a player's customary participation on the day following the day of onset.

"Any fracture that occurs, even though the athlete does not miss any regularly scheduled session. 
"Any dental injury, including fillings, luxations, and fractures.

"Any mild brain injury that requires cessation of a player's participation for observation before returning, either in the current session or the next session" (Powell and Barber-Foss, 1999, p. 278).

The preceding examples indicate the operational nature of the definition of an injury used in surveys of youth sports. Nevertheless, a common thread in all definitions is that an injury involves removal from participation in a sport.

\section{I. Acute and Overuse Injuries}

Injuries can be classified in several ways. Many studies focus on injury type (abrasion, sprain, fracture, mild traumatic brain injury, etc.), anatomical location of injuries (head, spine/trunk, lower extremity, upper extremity), and perceived injury severity (mild, moderate, severe). Injuries are also defined as acute, overuse and chronic.

Acute injuries refer to a major traumatic event (macrotrauma), such as a fracture, sprain, contusion, laceration, concussion, and others. Acute injuries are generally represented in the injury records of emergency rooms, insurance records, sports medicine clinics, and so on.

Overuse injuries are a consequence of repetitive microtrauma below the threshold associated with acute injury. They are associated with excessive repetitions of a specific sport activity as in baseball pitching, swimming, and distance running. Overuse injuries commonly occur at joint surfaces; thus sport specific labels are often used, e.g., Little League and tennis elbow, and swimmer's shoulder. Overuse is also implicated in stress fractures, especially when the mineral integrity of a bone is compromised as in young female distance runners and gymnasts. Overtraining is an important issue in overuse injuries associated with sport.

The term chronic refers to an injury that persists over a long period of time. A chronic injury may result from overuse and/or acute injuries.

Many discussions of injuries in youth sports focus on characteristics and/or conditions that might place a youngster at risk for an injury (Micheli, 1985; Caine and Lindner, 1990). These are labeled as "risk factors." Potential risk factors are commonly described in the context of the young athletes, i.e., player-related or internal risk factors, and in the context of the sport environment - external risk factors. Needless to say, interactions between the athlete and the sport environment are central to injuries. 


\section{I. Internal Risk Factors}

Potential risk factors related to the young athlete include the following:

- Physique, the child may not have the body build suitable for a specific sport;

- $\quad$ Problems in structural alignment;

- $\quad$ Lack of flexibility;

- $\quad$ Lack of muscular strength or strength imbalance;

- Marginal and/or poor skill development;

- Behavioral factors, including risk taking and inability to cope with stress;

- Injury history, specifically inadequate rehabilitation from prior injury;

- $\quad$ The adolescent growth spurt: individual differences in timing and tempo, strength imbalance, reduction in flexibility, adolescent awkwardness;

- Maturity-associated variation, maturity mismatches in size and strength, late maturation.

The contribution of internal risk factors of young athletes to injuries in sports is neither known with certainty nor specified. There is a need for more specific information on the unique aspects of these factors, and perhaps others, that may place a young athlete at risk for an injury. For example, what is it about the growth spurt that places the adolescent sport participant at risk? The association between increased prevalence of injuries and the adolescent growth spurt has been long recognized (e.g., Dameron and Reibel, 1969). The term association needs to be emphasized. There are no prospective or longitudinal data that relate injuries to parameters of the adolescent growth spurt. Youth who present to a clinic with an injury are ordinarily seen only on this occasion and it is virtually impossible to estimate where a child is in his or her growth spurt based on one observation.

Longitudinal data on bone mineral accrual during the adolescent growth spurt indicate that the peak velocity of growth in bone mineral content occurs after peak velocity of growth in height by more than one year, on average (luliano-Burns et al., 200I). The lag in bone mineral accrual relative to linear growth may suggest a period of skeletal "fragility" which might contribute to the increased occurrence of injuries (sport and non-sport) during the adolescent spurt.

Other changes during the adolescent growth spurt also need consideration. Loss of flexibility, for example, is indicated as a risk factor. Flexibility, however, is joint specific and is a highly individual characteristic. Girls, on average, are more flexible than boys, and the range of motion of some 
joints increases during puberty in contrast to the general suggestion that flexibility decreases. Loss of flexibility in athletes during adolescence may be sport specific, e.g., shoulder and back flexibility in tennis players or loss of quadriceps flexibility in soccer players (Kibler and Chandler, 1993). Although flexibility and strength (static and explosive) are not related, it has been suggested that an imbalance between strength and flexibility may lead to abnormal movement mechanics, which in turn may be a risk factor for injury.

Peak gains in muscular strength and power occur, on average, after peak gains in height and closer in time to peak gains in body weight. Does this contribute to the strength imbalance described in some adolecent athletes? The role of "adolescent awkwardness," which is often attributed to rapid growth (see Malina et al., 2003), also needs consideration in the context of injuries.

Maturity-associated variation in body size, strength, power and other performance characteristics are magnified during the transition into adolescence (9-13 years) and in adolescence per se ( $14-18$ years). Hence, an important question is the following: What is the contribution of maturity mismatches in size, strength and power to injuries? Unfortunately, the maturity status of youth sport participants has not be systematically related to injury.

Finally, given the association among age, experience, growth, and maturation, is age of participants a specific risk factor? How do age, experience, growth and maturation interact in the context of sport injuries? Is lack of skill a risk factor? Are the more skilled more able to avoid the risk of injury, or are the less skilled less likely to avoid the risk of injury?

\subsection{External Risk Factors}

Potential risk factors associated with the sport environment include the following:

Inadequate rehabilitation from prior injury - loss of conditioning, flexibility and strength;

262 Training errors - improper technique, lack of adequate instruction, use of inappropriate drills, lack of conditioning; Playing conditions - structural hazards: goal posts, fences, sprinklers; surfaces: uneven, wet, foreign materials; environment: lighting, heat/cold, humidity, lightning; proximity to spectators;

- $\quad$ Equipment - availability, improper and ill . fitting, "hand-downs;" equipment required to play (goals, bats); equipment required for protection (pads, helmets); equipment that is optional for protection (mouth guards); maintenance of equipment; 
- $\quad$ Age groups - size, maturity and experience mismatches in broad age groups;

- Coach behaviors - inappropriate drills and techniques, poor instruction, forced participation of an athlete after injury or incomplete rehabilitation;

- Parent behaviors - unrealistic expectations, pushing a child too fast, having a child "play-up" in an older age group;

Sport organizations (administrators, coaches, and officials) increased tolerance for aggression and body contact in some sports (ice hockey, soccer, football, basketball).

The unique feature about risk factors related to the sport environment is that they can be controlled and perhaps modified to reduce the risk of injury. External risk factors in youth sports are largely under the control of coaches, parents and sport administrators, i.e., adults.

There have been several successful efforts at reducing injuries in sport by introducing changes in the sport environment. These include the intrroduction of breakaway bases in youth baseball and softball, elimination of the trampoline from high school gymnastics competition, and elimination of "spearing" or spear tackling in football (Hergenroeder, 1998). Nevertheless, introduction of changes designed to prevent injuries in a sport is a difficult process. The difficulties and related complexities are especially evident in efforts to introduce softer and safer baseballs, Reduced Injury Factor (RIF) baseballs (Hergenroeder, 1998).

Although factors in the sport environment are potentially manageable from the perspective of injury prevention, it is somewhat myopic to suggest that injuries would not have occurred had circumstances been ideal. And, the assumption that many injuries among youth sport participants are preventable must be substantiated in terms of specific risk factors and sport contexts, and effective interventions. Hergenroeder (1998) presents an excellent discussion of issues related to the prevention of injuries in youth sports.

One intervention that is often mentioned in the prevention of youth sport injuries is the education of coaches. However, sound data to the effectiveness of coaches in the prevention of injuries are lacking. An early study of high school football injuries (Blyth and Mueller, 1974) suggests an inverse assocation between age of the coach and injury rate of their teams, i.e., coaches with more experience (20+ years) have a lower injury rate than coaches with less experience ( $<5$ years). This, of course, is the high school level, and given the stresses associated with coaching at his level, the number of coaches with $20+$ years experience is probably very small. At younger age levels, coaches have much less experience. In many youth sport programs at 
local levels, the majority of coaches are volunteers, very often with minimal experiences in the sport and little formal training in teaching children in the context of the sport. The ranks of volunteer coaches also experience major turnovers on an annual basis. In other words, adults who work with youth sport programs are a transient population.

Coaches can be influential in the prevention and/or occurrence of injuries. Many risk factors for injury are to some extent under the control of coaches (see above), and coach education programs often place emphasis on injury prevention. Does coach education play a significant role in the prevention of injuries? Data are presently unavailable to evaluate the role of coach behaviors and/or coach education programs in the prevention of injuries.

Although the education of coaches may be important to the safety of youth sport participants, several important questions need to be addressed. What is the role of the youth sports coach in the prevention of injuries, and in providing first aid and/or health care for injuries? How can coach education programs be improved to enhance injury prevention? Coaches should be educated about awareness of safety issues in the respective sport and in the recognition of and response to injuries. Coaches should also be prepared to provide first aid and should have an emergency medical reponse plan in place. Given concern for litigation associated with the on-field care of injured athletes, coaches may also be expected to show competence in cardiopulmonary resuscitation and advanced first aid (see American Red Cross, 1997). Coaches need to be aware of the legal implications of injuries sustained by youth who are under their supervision in sport. For example, what are the potential legal consequences for failing to act in case of an injury, or for selecting an improper course of action, or for selecting a proper course of action but failing to carry it out in the correct manner?

Parents can assist coaches in injury prevention by providing information to coaches and others involved with the administration of youth sport programs on the medical history and specifically the injury history of the child or adolescent athlete. They should likewise insure that their child is completely recovered or rehabilitated from an injury before permitting him/her to return to the sport. Since previous injury is a risk factor for future injury, it is important that coaches in cooperation with parents ensure complete rehabilitation, modify training demands to accommodate the rehabilitation process, and of course, be able to recognize symptoms related to the injury.

\section{INJURY RATES}

The term rate refers to a ratio between two things. In sport injury epidemiology, several rates have been defined. As an example, several specific 
incidence rates were used in the National Athletic Trainers Association survey of injuries among high school athletes (Powell and Barber-Foss, 1999):

- case rate/100 players $=$ number of injuries/total number of players

- $\quad$ player rate/ 100 players $=$ number of players sustaining at least I injury/total number of players

- $\quad$ case rate/ 100 athlete exposures $=$ number of injuries/number of athlete exposures.

Specific case rate per athlete exposure can be calculated separately for practices and games, and these can then be compared in the incidence density ratio: game injury rate/practice injury rate

Estimates of injury rates among youth sports participants are variable and limited, especially limited for local, agency sponsored, club and recreational sports. On the other hand, injury data are more systematically available for interscholastic sports, intercollegiate and professional sports.

Available studies of young participants are often limited to clinical observations and do not include suitable athlete exposure data, i.e., opportunities for injury, for practices and competitions. Focus is on the injured and data for athletes who are not injured are not reported or retained in order to derive rate estimates. Exposure data, i.e., all youngsters involved in a practice or a game, provide the denominator that is necessary for estimating rates.

\section{SOURCES OF DATA ON INJURY}

Sources of data on injuries in youth sport participants are diverse. They include accident reports, clinical records (hospitals, emergency rooms, sport injury clinics), insurance records, interviews, retrospective questionnaires, and various combinations of information. Such studies provide estimates of age-, sex- and sport-associated variation in the occurrence and type of injuries, but the rate of injuries is not known and the specific context of injuries is not ordinarily considered. The definition of an injury and reporting protocol are not standardized among studies. Some injuries are defined as a sport injury if the youngster was using a piece of sports equipment at home and not involved in an organized form of the sport. The NATA high school injury surveillance project utilized certified athletic trainers who worked directly with school athletic programs and a standardized reporting protocol (Powell and Barber-Foss, 1999).

Data from clinical series, case reports, and insurance company statistics are limited because only individuals who are presented to medical and/or insurance personnel are included. Individuals who are injured, but who are not 
presented to medical and/or insurance personnel, are not represented in the statistical base. Thus, they probably underestimate the true incidence of injuries in sport, since it is likely that many minor injuries are unreported or self treated. Further, only more severe and catastrophic cases are often included in clinical series and case reports.

The National Electronic Injury Surveillance System (NEISS) is a program utilized in the United States. It is limited to injuries that require medical care in a hospital emergency room (Mueller and Blyth, 1982). The NEISS data provide national projections, but the data are limited in their utility in identifying the sport-specific context of the injuries and in establishing injury rates because information on the number of exposures is lacking.

Systematic procedures for collecting information on injuries associated with participation in sport are not in place, and there is a recognized need for such information from the perspective of public health. Intercollegiate programs in the United States have systematic procedures in place. There is also a need to systematically collect information on numbers of participants and exposures, or perhaps duration of participation and exposures, in practices and competitions in youth sports programs at the local level. This is important from two perspectives, first, to obtain estimates of the prevalence and incidence of injuries in youth sports, and second, with this information in place, to develop preventive measures with the goal of preventing andreducing the incidence of injury in youth sport.

\section{INJURY SURVEYS}

It is beyond the scope of this discussion to summarize results of injury surveys of youth involved in sport. Surveys generally fall into three categories: general, multiple sport, and sport-specific. Several examples of each will be subsequently indicated.

\section{I. General Surveys}

Two general surveys are cited as examples. The Child Health Supplement to the 1988 National Health Interview Survey conducted by the

266 United States National Center for Health Statistics provides an estimate of the incidence of injuries associated with sport and recreational activities (Bijur et al., 1995). The survey considers non-fatal accidents, injuries or poisoning in children and adolescents $5-17$ years of age that received medical attention in 1988. The data were reported by an adult in the households surveyed, most often the mother of the youngster. Data from the National Health Interview Survey do not include information which would permit estimates for organized sports, for specific sports, and for the sport-specific context of the injuries. 
The Canadian Hospitals Injury Reporting and Prevention Program (CHIRPP) is an emergency room-based injury surveillance program in ten pediatric hospitals, which specifically identifies sport injuries among other types of injuries in children and youth 5-17 years (Ellison and Mackenzie, 1993). In contrast to the United States interview data, the CHIRPP survey provides sport specific information.

Such surveys provide general trends for sport-related injuries in children and adolescents. The number of injuries increases with age and reaches a peak during adolescence; peak age of occurrence is earlier in girls than in boys by about two years. Hence, the adolescent growth spurt and/or associated behaviors may be implicated in sport-related injuries. Injuries occur more often in boys than in girls, but the studies do not control for sex differences in numbers of participants, i.e., more boys than girls generally participate. Fractures, sprains/strains, and contusions are the most commonly reported and/or treated injuries. The surveys focus almost exclusively on acute injuries. Overuse injuries are not ordinarily considered.

\subsection{Surveys of Multiple Sports}

Three types of surveys of young athletes involved in several sports are briefly described. The reader is referred to the original reports for specific injury data.

The Training of Young Athletes (TOYA) study in the United Kingdom was a mixed-longitudinal study of elite young athletes, 8-16 years of age, in four sports - soccer (boys only), gymnastics, swimming and tennis, from 1987 through 1990. An injury was defined as one that occurred as a result of participation in sport and that had one or both consequences: reduction in sport activity or need for treatment. The context (practice, competition, nonsport), and overuse and acute injuries were considered (Sports Council, 1992; Baxter-Jones et al., 1993).

National registry data in Finland provide the basis for a survey of acute sport injuries (Kujala et al., 1995). Participants in competitive soccer, ice hockey, volleyball, basketball, judo or karate were required to obtain a license from the respective sport organizations, and for four of the sports, the license was related to an insurance policy, which covered acute sport injuries (insurance was not compulsory in two sports but the majority of participants had coverage). The data are based on sport participants linked to insurance records. Of relevance to the present discussion,data are reported for participants $<15$ years and $15-19$ years.

The National Athletic Trainers Association (NATA) surveillance of high school injuries during the 1995-I academic years permits comparisons of five 
sports in males and five sports in females (Powell and Barber-Foss, 1999, 2000). The NATA project also permits comparison of similar (baseball/softball) or the same (basketball, soccer) sports in males and females. A standardized definition of injury was used (see above), and all injuries were reported by certified athletic trainers.

\subsection{Surveys of Specific Sports - European Football (Soccer) as an Example}

It is beyond the scope of this brief review of injury in youth sports to cover the many sports available for children and adolescents. Examples from one sport will suffice. Participation in youth soccer programs is world wide and has increased dramatically in the United States over the past two decades. From the perspective of injury, soccer in many countries presents three interesting features. First, the sport has a high frequency of weekend or 4-5 day tournaments, which require participation in several games over a rather concentrated period of time. Second, there is increased popularity of soccer programs for girls so that concern for potential sex differences in the incidence of injuries has been expressed. Third, special summer camp programs, which include intense exposure to training and competition over a limited time, usually about one week, are increasing in popularity.

Estimated injury rates in youth soccer derived from two 5 day soccer tournaments in Norway and Denmark, about 15 years apart, are subsequently summarized. The first is based on international tournaments in 1975 and 1977 which included 1,549 teams, 25,000 players II-18 years of age, and 2,987 games (Nilsson and Roaas, 1978, p. 358). During the course of the tournament, $56 \%$ of all consultations with the medical staff were for injuries during games, 32\% were for other injuries and accidents, and 12\% were for illness. Overall, the estimated incidence of injury was about twice as large in girls as in boys, $44 / 1000$ versus $23 / 1000$ hours of play. When minor medical concerns were eliminated (skin abrasions and blisters, 39\% of all medical consulations), the sex difference in the estimated incidence of injuries was greater, 32/1000 versus 14/1000 hours of play. The authors attributed the sex difference in injuries to limited experience, training and skill in girls. Another factor may be age grouping. Males were categorized into four 2-year age groups, II-12,13-14, etc., whereas females were placed into two broader age groups, II-14 and I5- I 8 years. There thus may have been a greater likelihood of size mismatches, particularly among younger female participants. Agespecific estimates of injuries among boys varied between 12 and 15/1000 hours of play among the four age groups; sex-specific estimates by age group for girls were not reported. The frequency of injuries was greater in the final rounds of the tournament, where winning teams played up to 3 games per 
day and fatigue could have been a factor, and the sex difference was $2: 1$ in favor of females. The three most commonly reported injuries (excluding abrasions and blisters) were contusions, sprains/strains, and fractures. About two-thirds of the injuries were to the lower extremities (Nilsson and Roaas, 1978).

In the more recent soccer tournament over five days and involving 12,907 boys and girls 10-19 years of age and 785 teams in 1991 (Andreasen et al, 1992), injuries were classified non-sport related and illnesses, minor injuries during a practice or game, and severe injury during a game (not permitted to play the next match or withing 24 hours). There was no sex difference in the relative frequency of injuries in each of the three categories. There also was no sex difference in the incidence of severe injuries, 3.6 and $4.4 / 1000$ hours of play in males and females, respectively. The incidence of severe injuries increased with age into adolescence, reaching a peak at 14-16 years in males and at 12-14 and 14-16 years in females. The authors attributed the peaks in severe injuries during the adolescent years to pubertal changes in physical characteristics, although specific details of the growth spurt and sexual maturation that may relate to the risk of injury in soccer were not considered. Consistent with the earlier tournament study, contusions, sprains/strains, and fractures were the three most common severe injuries, and $77 \%$ of the injuries occurred while the injured youth was in contact with another player. Severe injuries occurred more often during the second half of games in both sexes, but the incidence of severe injuries did not differ between games played in qualifying and final rounds of the tournament.

In the context of a special one week summer camp for soccer, injuries were limited to problems that resulted in missing full participation in one or more camp sessions (Backous et al., 1988). The relative number of injuries tended to increase with age from 6 to 17 years, with the greatest percentage occurring in youth $\mathrm{D} 5 \mathrm{5}$ years of age. Overall, the estimated rates of injuries were 7.3 and 10.6/1000 hours for boys and girls, respectively. The most common injuries were contusions and strains/sprains ( $>80 \%$ of reported injuries), and about one-half of the injuries occurred as a result of contact with other players.

A factor that may influence the occurrence of injuries in soccer (and in other sports as well) is level of competition. Among Dutch male soccer players 13-18 years of age, the rate of injuries during the course of a season was greater in teams at a higher level of play (elite/select) compared to those at a lower level of play. Interestingly, about one-half of the injuries present in the soccer players before the start of the survey (48\%) and about one-third of 
the injuries incurred during the survey (35\%) were classified as overuse (Inklaar et al., 1996).

Potential consequences of "heading" the ball in soccer is receiving more attention. In a current review, the American Academy Pediatrics (2000, p. 660) emphasized the need for further research on the safety of heading in youth soccer:

"Currently, there seems to be insufficient published data to support a recommendation that young soccer players completely refrain from heading the ball. However, adults who supervise participants in youth soccer should minimize the use of the technique of heading the ball until the potential for permanent cognitive impairment is further delineated."

The American Academy of Pediatrics (2000) also draws attention to the occurrence of fatalities in youth soccer. Though rare, soccer-related fatalities were almost always the result of traumatic contact with goalposts or of falling goalposts, most often in younger players. This has implications for safety procedures relating to securing soccer goalposts during play as well as when they are not in use.

\section{SUDDEN DEATH IN YOUNG ATHLETES}

Among inherent risks in sport is the risk of death. Deaths at young ages, specifically in the context of sport, are rare. Nevertheless, when death occurs in a young athlete, media attention is often considerable. It is important, therefore, to be aware of the remote possibility of sudden death in sport and of the need for shared responsibility for sports safety among athletes, parents, coaches, and sport organizations.

Several recent reports have described individual cases of sudden death in sport that have been accumulated over relatively long periods. Maron et al. (1995) presented the clinical profile of 25 children and adolescents 3-19 years of age who died from cardiac arrest while participating in organized or recreational sports from 1977-1995. The 25 cases, 24 males and one female,

270 collapsed with cardiac arrest after receiving an unexpected blow to the chest. Death ensued from "commotio cordis" or "cardiac concussion." The specific cause of the deaths is not known with certainty, but may be related to the thinness of the chest wall in children and adolescents, which yields to the force of the projectile or blow, thus facilitating the transmission of the force to the heart. The sex difference in prevalence is probably related to the greater number of young males involved in sport, although other unidentified factors may be involved. 
Two other reports have considered cases of sudden death in adolescents and young adults associated with vigorous exercise (Van Camp et al., 1995; Maron et al., 1996). The former described 160 cases of nontraumatic death in high school and college athletes, 13 to 23 years of age, in a variety of sports between 1983 and 1993 (Van Camp et al., 1995). The ratio of males to females was about 10 to I, 146 males ( $16.9 \pm$ years) to 14 females ( $16.2 \pm$ years). The latter described the clinical profile of 134 athletes, 12 to 40 years of age, who suddenly died of cardiovascular-related complications in sport between 1985 and 1995 (Maron et al., 1996). Ninety percent of the athletes died during or immediately after a training session or an athletic competition. The ratio of males to females was again about I0 to I, 120 males to 14 females. The median age at death was 17 years, i.e., one-half of the cases were between 12 and 17 years of age.

In both studies, the major contributor to sudden death from cardiovascular causes during sport was hypertrophic cardiomyopathy, a pathological thickening of the walls of the left ventricle that obstructs blood flow from the left ventricle to the aorta. The majority of cases had no symptoms. The second most common cardiovascular cause of death in both studies was congenital anomalies of the coronary arteries. A variety of rare cardiovascular conditions as well as several apparently "normal hearts" were represented in the remainder of cases of sudden death in young athletes. A relatively large number of non-cardiovascular causes (30 of 136) of sudden death were identified in the high school and college athletes. These included 13 from hyperthermia, 3 from electrocution due to lightening, and 4 associated with asthma. All of these are preventable conditions.

What are the implications of these studies of sudden death for youth sports? Parents, coaches, and youth sports administrators should be aware of inherent risks in sports, including the rare possibility of death. A meeting sponsored by the National Athletic Trainer's Association, Research and Education Foundation (October 1996) highlighted the awareness of the problem of sudden death in athletes, particularly nontraumatic deaths. Several preventive procedures were discussed: (I) requiring a proper preparticipation physical examination, but recognizing that such an examination does not guarantee that cardiovascular problems will necessarily be identified; (2) taking on field preventive measures, especially in the context of non-cardiovascular causes of sudden death, e.g., hydration of athletes, scheduling practices at the right time of the day so as to avoid the hottest times of the day, awareness of lightening and thunderstorms in the area; (3) monitoring athletes on the field, i.e., be aware of "red flags" or who is having trouble; and (4) having an emergency plan in place for practices and games, e.g., cardiopulmonary rescusitation training, access to a telephone, etc. 


\section{SUMMARY}

Risk of injury is inherent in sport as well as in many other activities of childhood and adolescence. It is not known with certainty, however, whether injuries in organized youth sports occur at a higher rate than in other activities of children and adolescents. Nevertheless, if prevention of injuries in youth sports is a major objective, they need to be understood better.

Presently available data for injuries in youth sports are largely focused on rates for specific sports. Data on the context (practice versus game, specific situations in practices or games) and mechanisms (collision, indirect versus direct force, shear forces) of injuries in specific sports are limited. There is little information about injuries at the player level, i.e., characteristics of the individual who is injured or who might be susceptible to injury.

There is a need for systematic collection of comprehensive data on injuries in youth sports, especially at local levels of competition. The vast majority of children have their first sport experiences and probably their first injury experiences at these levels. Data for older ages and the high school level are more extensive, but generalization from older to younger ages may not be relevant and/or need to be made with caution.

Although injury in sport is commonly discussed in the medical and youth sport communities, it is not known with certainty whether there has been a real increase in the number of injuries. Is the "increase" in youth sports injuries real or perceived? Much of the data for youth sports at the local level generally lack suitable exposure data to estimate rates. By and large, however, youth sports are safe activities and most injuries are minor. Severe injuries do occur, and it is essential that adults who work with youth sports (coaches, league administrators, parents) be prepared to provide competent, timely and effective care those who are injured.

\section{REFERENCES}

American Academy of Pediatrics (2000) Injuries in youth soccer: A subject review. Pediatrics 105: 659-661.

272 American Red Cross (1997) Sport Safety Training Handbook. St. Louis, MO: Mosby Lifeline.

Andreasen I, Fauno P, Lund B, Lemche P, Knudsen H (1992) Soccer injuries among youth. Scand J Med Sci Sports 3:62-66.

Backhous DD, Friedl KE, Smith NJ, Parr TJ, Carpine WD (1988) Soccer injuries and their relation to physical maturity. Am J Dis Child I42: 839-842.

Baxter-Jones A, Maffulli N, Helms P (1993) Low injury rates in elite athletes. Arch Dis Child 68: I30- 132.

Behrman RE (ed) (2000) Unintentional injuries in childhood. The Future of Children 10, no I (Spring/Summer). 
Bijur PE, Trumble A, Harel Y, Overpeck MD, Jones D, Scheidt PC (1995) Sports and recreation injuries in US children and adolescents. Arch Pediatr Adolesc Med 149: 1009-1016.

Blyth CS, Mueller FO (1974) Football Injury Survey, Part 3: Injury rates vary with coaching. Phys Sportsmed 2: 45-50 (Nov).

Caine DJ, Lindner K (1990) Preventing injury to young athletes. Part I: Predisposing factors. Can Ass Health Phys Educ Rec J 56: 30-35 (Mar/Apr).

Dameron TB, Reibel DB (1969) Fractures involving the proximal humeral epiphyseal plate. J Bone Joint Surg 5 IA: 289-297.

DeLee JC, Farney WC (1992) Incidence of injury in Texas high school football. Am J Sports Med 20: 575-580.

Ellison LF, Mackenzie SG (1993) Sports injuries in the database of the Canadian Hospitals Injury Reporting and Prevention Program - an overview. Chron Dis Can I4: 96-104.

Hergenroeder AC (1998) Prevention of sports injuries. Pediatrics 10 1: 1057- 1063.

Inklaar H, Bol E, Schmikli SL, Mosterd WL (1996) Injuries in male soccer players: Team risk analysis. Int J Sports Med 17: 229-234.

luliano-Burns S, Mirwald RL, Bailey DA (200I) The timing and magnitude of peak height velocity and peak tissue velocities for early, average and late maturing boys and girls. Am J Hum Biol I3: I-8.

Kibler WB, Chandler TJ (1993) Musculoskeletal adaptatioins and injuries associated with intense participation in youth sports. In BR Cahill, AJ Pearl (Eds): Intensive Participation in Children's Sports. Champaign, IL: Human Kinetics. Pp: 203-2I6.

Kohl HW, Malina RM, Campaigne BN, Dick RW, Duda JL, Harris SS, Hergenroeder AC, Jones BA, Murray DG, Seefeldt V (1996) Youth sports injury: Risks, causes and consequences. Indianapolis: American College of Sports Medicine Roundtable.

Kujala UM, Taimela S, Antti-Poika I, Orava S, Tuominen R, Myllynen P (1995) Acute injuries in soccer, ice hockey, volleyball, basketball, judo, and karate: Analysis of national registry data. BrMed J 31 I: | 465- | 468.

Maffulli N, Chan KM, Macdonald R, Malina RM, Parker AW (200I) Sports Medicine for Specific Ages and Abilities. London: Churchill Livingstone.

Malina RM, Bouchard C, Bar-Or O (2003) Growth, Maturation, and Physical Activity, 2nd edition. Champaign, IL: Human Kinetics, in press.

Maron BJ, Poliac LC, Kaplan JA, Mueller FO (1995) Blunt impact to the chest leading to sudden death from cardiac arrest during sports activities. New Engl J Med 333: 337-342.

Maron BJ, Shirani J, Poliac LC, Mathenge R, Roberts WC, Mueller FO (1996) Sudden death in young competitive athletes: Clinical, demographic, and pathological profiles. J Am Med Assoc 276: 199-204.

Micheli LJ (1985) Preventing youth sports injuries. J Phys Educ Rec Dance 56: 52-54 (Aug).

Mueller F, Blyth C (1982) Epidemiology of sports injuries in children. Clin Sports Med I: 343-352.

Nilsson S, Roaas A (1978) Soccer injuries in adolescents. Am J Sports Med 6: 358-36I.

Powell JW, Barber-Foss KD (1999) Injury patterns in selected high school sports: A review of the 1995-1997 seasons. J Athl Train 34: 277-284. 
Powell JW, Barber-Foss KD (2000) Sex-related injury patterns among selected high school sports. Am J Sports Med 28: 385-39l.

Roberts WO, Brust JD, Leonard B (1999) Youth ice hockey tournament injuries: Rates and patterns compared to season play. Med Sci Sports Exerc 31: 46-5I.

Sports Council (1992) TOYA and Sports Injuries. London: The Sports Council.

Van Camp SP, Bloor CM, Mueller FO, Cantu RC, Olson HG (1995) Nontraumatic sports deaths in high school and college athletes. Med Sci Sports Exerc 27: 64 I-647. 
Série

Investigacão

Coimbra

Imprensa da Universidade

2004 